КОЛТАШОВ Василий Георгиевич - преподаватель кафедры политической экономии и истории экономических учений Российского экономического университета им. Г.В. Плеханова (117997, Россия, 2. Москва, Стремянный пер., 36; koltashov@gmail.com); руководитель Центра политэкономических исследований Института нового общества

\title{
НЕОМЕРКАНТИЛИЗМ ПОСЛЕ БОЛЬШОГО КРИЗИСА: КАКОЙ БУДЕТ НОВАЯ ПОЛИТИЧЕСКАЯ И ЭКОНОМИЧЕСКАЯ ЭПОХА И ПОЧЕМУ
}

Аннотация. В статье рассматривается, как формирование теории больших циклических экономических кризисов промышленного капитализма обеспечило успешный прогноз кризисной эпохи 2008-2020 гг. и создало основу понимания новых - посткризисных - условий развития. В годы современного кризиса мир совершил поворот от неолиберальной к неомеркантильной модели экономических отношений. Этим определяется характер начинающейся политической эпохи. Главным в ней будет соперничество старых и новых (евразийских и не только) центров капитализма. Крах Вашингтонского консенсуса и возвращение политики протекционизма означает резкое повышение роли государства. В 2020 г. эпоха большого мирового кризиса приблизилась к концу; новый период развития будет характеризоваться быстрым экономическим ростом и острыми геополитическими противоречиями, что будет только стимулировать рост через рациональные и эффективные экономические и социальные решения.

Ключевые слова: неомеркантилизм, экономика, политика, кризис, большой кризис, центры капитализма, полупериферия, глобальные противоречия

$\mathrm{K}$ ак теория больших кризисов промышленного капитализма позволяет увидеть контуры рождающегося неомеркантилизма, посткризисную карту конфликтов держав? И почему же нужно быть уверенными в новом экономическом подъеме?

В начале июня 2008 г. в России был опубликован аналитический доклад «Кризис глобальной экономики и Россия» 1 . Он не остался незамеченным и был тут же переведен на английский язык. В этом документе, подготовленном под руководством автора статьи, миру был обещан долгий и острый экономический кризис. Прогноз не замедлил начать реализовываться. Однако он не был чисто экономическим, сконцентрированным на фондовой бирже, продажах или долгах корпораций и правительств. Предполагались технологические и политические изменения, что должно было создать условия для развития новых центров. Время «свободной торговли» с кризисом обрывалось, и вероятным виделось возвращение протекционизма и сильных национальных правительств, жестких в регулировании национального рынка и отстаивании интересов вовне.

Строился анализ на изучении длительного периода развития капитализма. Но тогда разбор не мог быть развернутым. В 2019 г. в монографии «Капитализм кризисов и революций: как сменяются формационные эпохи, рождаются длинные волны, умирают реставрации и наступает неомеркантилизм» автор перечислил признаки уже идущих перемен и назвал начинающуюся эпоху неомеркантильной [Колташов 2019]. Более полное изучение больших экономических кризисов, подобных пережитому миром в 2008-2020 гг., готовится к публикации, однако неизменным остается главное: новая - посткризисная - эпоха будет строиться на соперничестве старых (США, ЕС, Великобритания и Япония) и

\footnotetext{
1 Кризис глобальной экономики и Россия: доклад Института глобализации и социальных движений (ИГСО). - Институт глобализации и социальных движений. 09.06.2008. Доступ: http:// igso.ru/world_crisis_and_russia/ (проверено 13.03.2020).
} 
новых (Китай, Россия, Индия и некоторые меньшие амбициозные государства) центров капитализма. Борьба на внешних и внутренних рынках будет борьбой и за рынки, и за свободу производить желаемый продукт без ограничений и вести торговлю к собственной выгоде, а не по нормам Вашингтонского консенсуса.

Приведет ли борьба к успеху новых центров? Да. Более того, она экономически необходима и является условием быстрого развития. Процесс этот займет, вероятно, ближайшие 25 лет и завершится новым крупным экономическим кризисом, который вновь изменит повестку дня на планете. Сейчас же только намечается выход из эпохи настоящего кризиса, и она не случайно является столь продолжительной: переживаемый миром с 2008 г. большой кризис есть кризис циклический и завершающий длинную волну развития (по Н. Кондратьеву). Позади мир оставляет понижательную волну, берущую начало из кризиса 19731982 гг. Впереди - повышательная волна, характерной чертой которой будет активное вовлечение внутренних ресурсов государств во имя ускорения роста. Все это будет происходить при помощи роста автоматизации производства, который можно назвать ренессансом робототехники. Появятся новые материалы и новые технологии их получения, а также будет вестись поиск решений по снижению цены генерации, передачи и сохранения электрической энергии.

Чтобы получить эту картину и понять всю суть глобального кризиса, автору статьи пришлось проделать немалую работу. Во-первых, нужно было понять роль кризисов до промышленного поворота развития капитализма, и даже задолго до торгового капитализма. Иначе невозможно было бы точно определить место современного кризиса в иерархии кризисов, отнюдь не сводимого к известному из экономических учебников. В конечном итоге должно было возникнуть новое понимание, новая теория особо сильных кризисов.

В порядке исторической хронологии производился обзор и анализ источников по вопросу экономических кризисов: фиксировалась великая поворотная роль кризисов III и XIV вв., за этим следовал анализ больших кризисов торгового капитализма, далеко не все из которых известны, после внимание должно было сосредоточиться на сведениях о кризисе 1770-х гг., первоначально фиксируемом как предполагаемый, что можно отнести и к ситуации 1810-1820 гг. Большой кризис 1770-1783 гг. выразил проблемы еще торгового капитализма, но после него мир вошел в период промышленного развития. После этого кризиса родилась и теория торгово-промышленных (средних или среднего цикла) кризисов. Классическая политическая экономия в лице К. Маркса дает наиболее полное понимание этого явления, вместе с тем выделяя необычные, особо острые поворотные кризисы, чему во многом была посвящен «Капитал» [Маркс 1983].

XIX в. преподнес миру еще несколько больших кризисов. Это были кризисы 1847-1850 и 1873-1879 гг. Каждый из них был поворотным: первый открыл путь широкому внедрению машин за пределами Англии и их серийному выпуску, а также бурному железнодорожному строительству; второй привел к революции в сталелитейной промышленности, обеспечил быстрый выпуск стальных паровых судов и колониальную экспансию, особенно в Африке. Позднее В. Ленин в работе «Империализм как высшая стадия капитализма» фиксировал еще одну крайне важную большую кризисную ситуацию - 1899-1904(7) гг. [Ленин 1969]. В XX в. были открыты волны Н. Кондратьева, фиксировались новые сильные и многое изменяющие в системе кризисы 1929-1933, 1947-1948, 1973-1982 гг. Разбор источников и первых взятых во внимание сведений показал накопление немалого числа первично проработанного исторического материала. Во второй половине XX в. огромный вклад в разработку проблемы внес отечественный экономист Л.А. Мендельсон. Он утверждал, что на стыке длинных волн име- 
ются особые большие кризисы, теории которых не существовало до проведенного исследования [Мендельсон 1959].

Теория больших кризисов начинается с определения их места в иерархии экономических кризисов и с прояснения самого вопроса об иерархии. Наивысший определяющий развитие уровень имеют великие кризисы (III и XIV вв.). Они создают условия для развития общества определенного типа. Большие кризисы капитализма появились благодаря кризису XIV в., но до конца третьей четверти XVIII в. они являются циклическими лишь условно. Это явление меняется, как только капитализм становится промышленным - изменяется в его центре, в английской экономике. С этого момента можно предположить (не имея еще данных по поворотам 1770-х и 1810-1820-х гг.): все большие кризисы промышленного капитализма расположены на стыке длинных волн Кондратьева, они начинают и завершают их. Внутри волн находятся средние циклы со средними кризисами, каковыми и являются те кризисы, что были проанализированы классической политической экономией.

Большие кризисы промышленного капитализма представляют собой особый вид кризиса перепроизводства, концепцию которого наиболее полно дал К. Маркс. Однако если средний кризис выполняет корректирующую функцию, то большой кризис - функцию изменяющую. Он продолжается от 3 до 15 лет, создавая целую эпоху кризиса в силу того, что для возобновления экономического роста становятся необходимыми глубокие общественные перемены в зоне центра, полупериферии, а иногда и периферии мировой системы. Задача структурных изменений в экономике не может быть решена в этом процессе без революции в технологиях, создания или форсированного развития новых отраслей. Большие кризисы меняются в процессе развития (могут становиться более затяжными, приобретают многоволновую структуру), но остаются механизмом смены длинных волн. Подробно концепция больших кризисов изложена в табл. 1. Здесь также дано сопоставление ее с концепций среднего кризиса.

Дав общие контуры теории больших кризисов более 10 лет назад, автор в исследовании вопроса дал теорию в деталях и подверг ее проверке через анализ всех больших кризисных ситуаций, имевших место с последней четверти XVIII в. Естественно, такая работа в 2007 г. еще не была проведена, она потребовала немалого времени. Подробно была восстановлена ситуация кризисов 1770-х и 1810-1820-х гг. (они впервые формально вводятся в научный оборот), менее детально делался разбор давно известных науке кризисов 1847-1850, 1873-1880, 1899-1904, 1929-1933, 1947-1948, 1973-1982, 2008-2020 гг. Все они имели особенности, но имели и общие черты. Их выявление обеспечило подтверждение ранее выдвинутой как гипотезе концепции больших кризисов промышленного капитализма. Особую проверку теории обеспечило наше время - 2008-2020 гг. Именно они показали ее практическую применимость для понимания процессов в мировой экономике и политике, которая в наше время переживает подъем.

В табл. 1 в общем варианте показано, почему современный кризис оказался столь продолжительным и должен был вызвать резкие перемены. Конкретно же он был порожден, с одной стороны, перенакоплением капитала, с другой исчерпанием возможности роста на основе старой базы - потребления в старых центрах глобального капитализма, к тому же утратившей во многом свою индустриальную основу. Но антикризисные меры монетарного типа смогли заставить кризис в 2009-2010 гг. отступить. Главной причиной возвращения его стала сама неолиберальная антикризисная политика, законсервировавшая на время ситуацию. Она проводилась как в США, так и в других странах. Р.С. Дзарасов 


\section{Таблица 1}

\section{Средние и большие кризисы промышленного капитализма}

\begin{tabular}{|c|c|c|}
\hline Критерии & $\begin{array}{c}\text { Экономический кризис } \\
\text { перепроизводства согласно } \\
\text { концепци Карла Маркса } \\
\text { (кризис в завершении } \\
\text { среднего цикла) }\end{array}$ & $\begin{array}{c}\text { Большой экономический кризис, } \\
\text { согласно волновой конщепщии развития } \\
\text { капитализма }\end{array}$ \\
\hline $\begin{array}{l}\text { Общая } \\
\text { причина } \\
\text { кризиса }\end{array}$ & $\begin{array}{l}\text { Основное противоречие } \\
\text { капитализма - противоре- } \\
\text { чие между общественным } \\
\text { характером производства и } \\
\text { капиталистической формой } \\
\text { присвоения }\end{array}$ & $\begin{array}{l}\text { Основное противоречие капитализма } \\
\text { - противоречие между общественным } \\
\text { характером производства и капиталисти- } \\
\text { ческой формой присвоения }\end{array}$ \\
\hline $\begin{array}{l}\text { Конкретное } \\
\text { выражение } \\
\text { причины } \\
\text { кризиса }\end{array}$ & $\begin{array}{l}\text { Товарное перепроизводство } \\
\text { в силу недостатка потреби- } \\
\text { тельского спроса; платеже- } \\
\text { способный спрос большин- } \\
\text { ства населения отстает от } \\
\text { роста производства }\end{array}$ & $\begin{array}{l}\text { Товарное перепроизводство в силу недо- } \\
\text { статка потребительского спроса; платеже- } \\
\text { способный спрос большинства населения } \\
\text { отстает от роста производства. При этом } \\
\text { достигнуты пределы его повышения в } \\
\text { результате преодоления кризисов по стан- } \\
\text { дартной схеме }\end{array}$ \\
\hline $\begin{array}{l}\text { Проявление } \\
\text { для капитала }\end{array}$ & $\begin{array}{l}\text { Избыточное инвестирова- } \\
\text { ние капиталов в производ- } \\
\text { ство и торговлю, вызыва- } \\
\text { ющее сгорание излишнего } \\
\text { реального капитала в про-- } \\
\text { цессе кризиса: сокращение } \\
\text { производства, закрытие } \\
\text { цехов и предприятий, озна- } \\
\text { чающее разрушение части } \\
\text { производительных сил }\end{array}$ & $\begin{array}{l}\text { Избыточное инвестирование капиталов } \\
\text { в производство и торговлю, вызывающее } \\
\text { сгорание излишнего реального капитала } \\
\text { в процессе кризиса: сокращение произ- } \\
\text { водства, закрытие цехов и предприятий, } \\
\text { означающее разрушение части произво- } \\
\text { дительных сил; перенакопление и воз- } \\
\text { можное сгорание капитала в огромных } \\
\text { масштабах; процесс имеет затяжной, а } \\
\text { часто и волновой характер: кризис не } \\
\text { отпускает и часто обманывает, приводя к } \\
\text { сгоранию инвестиций, сделанных в рас- } \\
\text { чете на скорый подъем }\end{array}$ \\
\hline $\begin{array}{l}\text { Механизм } \\
\text { преодоления } \\
\text { кризиса }\end{array}$ & $\begin{array}{l}\text { Восстановление динами- } \\
\text { ческого равновесия между } \\
\text { спросом и предложением в } \\
\text { условиях пониженных цен } \\
\text { на товары за счет обновле- } \\
\text { ния основного капитала, } \\
\text { совершенствования произ- } \\
\text { водства. В результате созда- } \\
\text { ются условия для нового } \\
\text { расширения производства }\end{array}$ & $\begin{array}{l}\text { Восстановление динамического равно- } \\
\text { весия между спросом и предложением в } \\
\text { результате возникновения или (и) фор- } \\
\text { сирования развития новых отраслей, } \\
\text { качественно меняющих процесс произ- } \\
\text { водства, например внедрение паровых } \\
\text { машин в промышленности при создании } \\
\text { машиностроения, замена пара электри- } \\
\text { чеством при возникновении автомо-- } \\
\text { билестроения и сетей электростанций. } \\
\text { Значение имеет также изменение соци- } \\
\text { альных условий производства (радикаль- } \\
\text { ные реформы и революци) и открытие } \\
\text { новых рынков, ранее находившихся за } \\
\text { пределами мирового капитализма или } \\
\text { имевших крайне ограниченные связи с } \\
\text { ним. Одновременно происходит обновле- } \\
\text { ние основного капитала и совершенство- } \\
\text { вание существующего производства, что } \\
\text { само по себе оказывается недостаточным } \\
\text { для преодоления кризиса }\end{array}$ \\
\hline $\begin{array}{l}\text { Когда имеет } \\
\text { место (фазой } \\
\text { какого цикла } \\
\text { является) }\end{array}$ & $\begin{array}{l}\text { Кризис завершает тор- } \\
\text { гово-промышленный цикл } \\
\text { 5-10 лет (цикл Клемана } \\
\text { Жюгляра) }\end{array}$ & $\begin{array}{l}\text { Кризис завершает длинную волну разви- } \\
\text { тия 20-30 лет (по Н. Кондратьеву) и явля- } \\
\text { ется механизмом запуска новой волны } \\
\text { развития, внутри которой происходят } \\
\text { обычные кризисы перепроизводства }\end{array}$ \\
\hline
\end{tabular}




\begin{tabular}{|c|c|c|}
\hline $\begin{array}{l}\text { Продолжи- } \\
\text { тельность } \\
\text { кризиса }\end{array}$ & Не более 2 лет & $\begin{array}{l}\text { От } 3 \text { до } 15 \text { лет (исключая особую ситуа- } \\
\text { цию 1948-1949 гг.) }\end{array}$ \\
\hline $\begin{array}{l}\text { Функция в } \\
\text { экономиче- } \\
\text { ском развитии }\end{array}$ & Корректирующая & Изменяющая \\
\hline $\begin{array}{l}\text { Затрудняющие } \\
\text { преодоле- } \\
\text { ние кризиса } \\
\text { факторы }\end{array}$ & $\begin{array}{l}\text { Усиление эксплуатации } \\
\text { рабочей силы }\end{array}$ & $\begin{array}{l}\text { Усиление эксплуатации рабочей силы, } \\
\text { пережитки феодальных отношений и } \\
\text { отсталые - реакционные - полити- } \\
\text { ческие системы, сложившиеся ранее } \\
\text { центр-периферические отношения между } \\
\text { странами (последнее подчеркивает, что } \\
\text { структурность кризиса не носит чисто } \\
\text { отраслевой характер и не ограничивается } \\
\text { также экономической политикой) }\end{array}$ \\
\hline $\begin{array}{l}\text { Особенности } \\
\text { развития } \\
\text { кризиса }\end{array}$ & $\begin{array}{l}\text { Накануне кризиса разви- } \\
\text { ваются биржевые спеку- } \\
\text { ляции (сырьем и ценными } \\
\text { бумагами), активно выда- } \\
\text { ется кредит, что создает } \\
\text { иллюзию спекулятивной } \\
\text { и финансовой природы } \\
\text { кризиса. Падение на бирже } \\
\text { приводит к вздорожанию } \\
\text { кредита и банкротствам; } \\
\text { увольнения еще более } \\
\text { сокращают потребитель- } \\
\text { ский спрос и обостряют } \\
\text { кризис }\end{array}$ & $\begin{array}{l}\text { 1) в преддверии кризиса биржевые спе- } \\
\text { куляции достигают особенной силы, что } \\
\text { приводит к большему падению, особенно } \\
\text { глубокому и затяжному кризису; } \\
\text { 2) торгово-промышленный цикл не } \\
\text { может начаться - так можно охаракте- } \\
\text { ризовать часто возникающую при таких } \\
\text { кризисах ситуацию, когда после падения } \\
\text { рынков и волны банкротств капиталисты } \\
\text { провели обновление основного капитала, } \\
\text { но это привело лишь к новому падению; } \\
\text { 3) после возникновения государственно- } \\
\text { монополистического капитализма и раз- } \\
\text { вития кейнсианской контрциклической } \\
\text { политики такие кризисы приобрели } \\
\text { ш-образную структуру; они стали распа- } \\
\text { даться на волны с чередующимися искус- } \\
\text { ственными оживлениями, в результате } \\
\text { работа кризиса растянулась по времени и } \\
\text { приобрела черты работы серии кризисов } \\
\text { (ситуации 1973-1982 и 2008-2019 гг.) }\end{array}$ \\
\hline $\begin{array}{l}\text { Зоны } \\
\text { возникновения } \\
\text { и преодоления }\end{array}$ & $\begin{array}{l}\text { Страны центра мирового } \\
\text { капитализма (отслежено } \\
\text { на английских кризисах } \\
\text { XIX в.) }\end{array}$ & $\begin{array}{l}\text { Страны центра и полупериферии миро- } \\
\text { вого капитализма, при этом возможен } \\
\text { переход стран из полупериферии в группу } \\
\text { центра и даже смена ролей }\end{array}$ \\
\hline
\end{tabular}

справедливо указывает, что неолиберализм - это «не что иное, как перерождение классического либерализма в свою противоположность» [Дзарасов 2016]. Неолиберализм как подход не продемонстрировал достаточную практическую гибкость, чтобы на его основе преодолеть кризис. Эта гибкость в экономической политике достигается лишь с отказом от него, решительным или постепенным, но всегда действенным.

В 2009-2016 гг. политика ФРС США стабилизировала финансовый рынок. Произошла, как отмечает Светлана Мудрова, трансформация структур участников этого рынка. Но если на Западе политика игроков стала более взвешенной, а регулятор (ФРС) стал более внимателен, то в Китае все сложилось иначе [Мудрова 2016]. Обвал на фондовом рынке КНР в 2015 г. стал одним из наиболее значимых проявлений второй волны кризиса (2013-2016 гг). Он наглядно показал: финансовые пузыри сохранились в одних странах и еще более надулись в других. Потребовался перевод экономической политики на неомеркантильные рельсы, чтобы экономический рост стал возможен. Именно это случилось в 
России под влиянием шоков 2014-2016 гг. Но ориентация на восстановление и расширение национального производства и товарного вывоза должна была привести к обострению отношений с Западом, который сделал свои выводы из возвращения кризиса в 2013-2016 гг. Его вывод состоял в том, что выросшие экономически и политически страны должны дать ресурсную подпитку старым центрам капитализма, прежде всего США, а не использовать их слабости для обогашения, выхода из кризиса и быстрого развития.

Проявившийся на этой основе конфликт обешает быть главным в предстоящей повышательной волне развития мировой экономики, а конкретно эпохи в 20-25 предстоящих лет. При этом характерно, что именно в Евразии складываются условия для превращения сильнейших экономик в новые центры капитализма. В результате центр мировой хозяйственной системы, как это уже не раз было прежде, расширится. Но разве это расширение хоть раз произошло без конфликтов, без соперничества и напряжения? И разве хоть единожды этот процесс обходился без стимулирующего воздействия больших кризисов?

Начинающаяся политическая эпоха обещает острую борьбу старых и новых центров. Это означает замену американской гегемонии турбулентными процессами, в которых уже видно сближение евразийских государств в самом широком смысле - не только в смысле создания ЕАЭС, но и в плане поиска взаимной поддержки и взаимного ограничения в некоторых случаях. Это особо касается Китая, чья активность не без основания взывает настороженность у стран-партнеров. Однако все эти евразийские государства должны будут решать спорные вопросы, чтобы эффективно защищать свои интересы в мире, где старые лидеры видят в них средство решения собственных проблем. Они именно поэтому выставляют столько претензий, вводят санкции и начинают торговые войны. Снятие этих противоречий не произойдет в скором времени: весь период повышательной длинной волны, предположительно до начала нового большого кризиса около 2045 г, развитие экономики будет связано с невероятной активностью международной и внутренней политики.

Едва ли шансы старых глобальных лидеров из числа $G-7$ на сохранение позиций в мировой политике велики. Они уже вынуждены отступать от своих требований и убеждаться в недейственности давления, которое скорее порождает поиск обходных и ответных мер. Хотя сторонники миросистемного анализа нередко говорят, что постсоветская Россия закрепится в положении одной из новых стран глобального центра. Но такие зоны мира, как Африка и Латинская Америка, становятся полем острой борьбы между старыми центрами и новыми претендентами на признание. Это признание будет получено в результате борьбы и потери старыми центрами многих геополитических и экономических позиций. Таким окажется, видимо, итог посткризисной экономической эпохи. Но и она порождена кризисом.

Эпоха до 2008 г. прошла под знаком конца истории. Современный кризис вернул истории бурное кипение жизни, и такова роль многих больших кризисов, особенно тех, что порождают повышательные волны - эпохи развития, где меняются не одни технологии, но и политический порядок.

\section{Список литературы}

Дзарасов Р.С. 2016. Неолиберализм и Россия. - Политэкономия кризиса. Om неолиберальной экономической модели к новому социальному государству (под ред. Р.С. Дзарасова, Б.Ю. Кагарлицкого, А.В. Очкиной). М.: Изд-во РЭУ им. Г.В. Плеханова. С. 41-42.

Колташов В.Г. 2019. Капитализм кризисов и революций: как сменяются форма- 
ционные эпохи, рождаются длинные волны, умирают реставрации и наступает неомеркантилизм. М.: Русайнс. 224 с.

Ленин В.И. 1969. Полное собрание сочинений: в 55 т. 5-е изд. М.: Госполитиздат. T. 27. C. 299-426.

Маркс К. 1983. Капитал: в 3 т. М.: Политиздат.

Мендельсон Л.А. 1959. Теория и история экономических кризисов и циклов: в 3 т. М.: Соцэкгиз.

Мудрова С.В. 2016. Трансформация структуры участников финансового рынка. - Центр инновационных технологий и социальной экспертизы. № 1. С. 7.

KOLTASHOV Vasiliy Georgievich, Lecturer at the Chair of Political Economy and History of Economic Studies, Plekhanov Russian University of Economics (36 Stremyanny Lane, Moscow, Russia, 117997; koltashov@gmail.com), Head of the Center for Political Economic Research, Institute of the New Society

\title{
NEO-MERCANTILISM AFTER THE LARGE CRISIS: WHAT WILL BE THE NEW POLITICAL AND ECONOMIC ERA AND WHY
}

\begin{abstract}
The article shows that the formation of the theory of large cyclical economic crises of industrial capitalism provided a successful forecast of the crisis of 2008-2020, and created the basis for understanding the new, post-crisis development conditions. During the years of the present crisis, the world has made a turn from the neoliberal model to the neo-mercantile model of economic relations. This determines the nature of the beginning of the political era. The main thing in it will be the rivalry of the old and new (Eurasian and not only) centers of capitalism. The collapse of the Washington Consensus and the return of protectionist policies mean a sharp increase in the role of the state. In 2020, the era of the great global crisis was drawing to a close; the new period of the development will be characterized by rapid economic growth and sharp geopolitical contradictions, which will only stimulate growth through rational and effective economic and social solutions.
\end{abstract}

Keywords: neo-mercantilism, economy, politics, crisis, large crisis, capitalism center, semi-periphery, global contradictions 